\title{
INRI DE RAÚL ZURITA: SUBVERSIÓN DEL HIMNO NACIONAL*
}

\author{
INRI BY RAÚL ZURITA: SUBVERSION \\ OF THE NATIONAL ANTH
}

\author{
Rafael Rubio \\ Pontificia Universidad Católica de Chile. Santiago, Chile \\ rirubio@uc.cl
}

\begin{abstract}
NRI fUe PUblicado el año 2003, inmediatamente después de Poemas MiL litantes (2000), texto con el que difiere en muchos sentidos, siendo el principal su manera de abordar la referencialidad. En su primera sección, el mar -ya no el mar cantado o descrito- es construido como una función dentro de una alegoría poética, susceptible de ser leída en clave histórica, contextual: la desaparición de cientos de cuerpos por parte de las fuerzas armadas de Chile, durante la dictadura militar de Pinochet, en que los detenidos fueron arrojados al mar vivos, desde aviones de la fuerza aérea, en distintas zonas del Océano Pacífico. Los cuerpos que caen son referidos o representados como las carnadas del cielo que caen sobre el mar, para ser devoradas por los peces, que son las tumbas del cielo. La caída de los cuerpos tiene como contraparte el movimiento ascensional de los peces hacia el final de la sección, susceptible de ser leído en clave cristiana: caída y ascensión de los cuerpos, sobre las aguas del mar. Las carnadas son cristos que caen en las cruces del mar, y el mar mismo es representado como el lugar de un sacrificio. Este correlato cristiano es coherente con el título mismo del poemario: INRI (Jesucristo, rey de los judíos), que es la inscripción que
\end{abstract}

\footnotetext{
* Este trabajo se ha desarrollado en el marco del Proyecto de Investigación Fondecyt No 1141152 (2013-2016), "Países y paisajes en la poesía de Raúl Zurita: diálogos, mutaciones y desapariciones (1971-2013)", cuya investigadora responsable es Paula Miranda y del cual soy co-investigador.
} 
pusieron los soldados romanos en la parte superior de la cruz, y que introduce en el poema la idea de la pasión y el sacrificio.

Chile mismo es representado como un largo pez que devora las carnadas del cielo, donde "pez" debe ser leído como el "Ictus", el símbolo bajo el que se reconocían los primeros cristianos, el pez devorador de hombres. Los peces que son las tumbas del cielo, en cuyo estómago santo caen los hombres como panes, comienzan su movimiento ascensional que niega la caída y la revierte. La ascensión de los peces con pedazos de cielo adentro, con carnadas digeridas con voracidad, implica dentro del código cristiano una posibilidad de redención, de retorno del dolor a la gracia. La relación entre el mar y la muerte nos remite, por otro lado, a la representación alegórica de Jorge Manrique en las "Coplas a la muerte de su padre", donde "nuestras vidas son los ríos que van a dar al mar, que es el morir" (48), versos cuya posible paráfrasis sería: nuestras vidas son los cuerpos que van a dar a la mar, que es el morir. El mar en Zurita funciona como una imagen de la muerte colectiva, en tanto pasión, desaparición y reparación del dolor infringido, reparación que en el epílogo es negada: "Cientos de cuerpos fueron arrojados sobre las montañas, lagos y mar de Chile. Un sueño quizás soñó que habían unas flores, que habían unas rompientes, un océano subiéndolos salvos desde sus tumbasen los paisajes. No. Están muertos. Fueron ya dichas las inexistentes flores. Fue ya dicha la inexistente mañana" (143). Lo que este fragmento niega es la posibilidad de una redención del dolor y una reparación de la muerte, por lo que el intertexto crístico en este punto trunca desoladoramente su realización. Se podría decir entonces que el intertexto bíblico e incluso el mismo título son invertidos en el poema en el sentido en que la posibilidad de una redención finalmente es negada. El INRI adquiere entonces una dimensión irónica e inconclusa: sólo se realiza la pasión, pero no la redención tan fundamental en el discurso cristiano. Otra alusión bíblica problematizada en el poema corresponde a la zarza que arde sin consumirse en el mar: "He allí el mar quemándose. Viviana oye cielos ardiendo entre las llamas del mar, zarzas que no se consumen, hijos de impresionantes zarzas que arden sin quemarse entre las llameantes olas" (26). "Zarzas de Chile, he allí a vuestros hijos. Zarzas de Chile, he allí el mar ardiendo" (25). El episodio referido corresponde a Exodo 3, que relata el momento en que Moisés, quien estaba cuidando las ovejas en Horeb, la montaña de Dios, vio al ángel del Señor entre las llamas de una 
zarza ardiente. La zarza estaba envuelta en llamas, pero no se consumía. Cuando el Señor vio que Moisés se acercaba a mirar, lo llamó desde la zarza. A esto Moisés se cubrió el rostro porque tenía miedo de mirar a Dios, pero el Señor dijo:

Ciertamente he visto la opresión que sufre mi pueblo en Egipto. Los he escuchado quejarse de sus capataces, y conozco bien sus penurias. Así que he descendido para librarlos del poder de los egipcios y sacarlos de ese país, para llevarlos a una tierra buena y espaciosa, tierra donde abundan la leche y la miel. Me refiero al país de los cananeos, hititas, amorreos, ferezeos, heveos y jebuseos. Han llegado a mis oídos los gritos desesperados de los israelitas, y he visto también cómo los oprimen los egipcios. Así que disponte a partir. Voy a enviarte al faraón para que saques de Egipto a los israelitas, que son mi pueblo (La Biblia Latinoamericana, 1972: 3.7).

La zarza ardiendo en el mar, funciona en el poema de Zurita como el testimonio de una promesa de salvación, de liberación, que se frustra finalmente al final del texto: "un sueño quizás soñó que habían unas flores, que habían unas rompientes, un océano subiéndolos salvos desde sus tumbas en los paisajes. No. Están muertos" (143). La liberación del pueblo de Israel se proyecta analógicamente sobre la liberación del pueblo de Chile, que no llega a concretarse, pero que se constituye como una promesa de la que la ascensión de los peces y la proliferación de las flores sobre el mar y la cordillera, son una imagen reiterativa.

No obstante, el mar desborda su sentido histórico y bíblico, para desplegar otros significados ¿Qué se dice del mar? "El mar, se dice del mar", equivalente a "el mar es el mar", tautología que excluye las metáforas que puedan elaborarse a partir de él. El sujeto no describe estéticamente el mar, sino la situación testimoniada que tiene lugar en él: la caída de los cuerpos desde los aviones. Pero el mar mismo, sus cualidades físicas o materiales, como su color, por ejemplo, no son referidas ni literal ni metafóricamente. El mar como un tabú del que solo puede decirse que es el mar. Así, el tropo más utilizado por Zurita en el poema es la sinestesia, recurso que le permite dar cuenta del mar desde la privación del sentido de la vista. La sinestesia se muestra como el intento desesperado por resolver la privación de un sentido a través de la agudización de otro. Entonces, se oye un cielo 
en lugar de ver un cielo. Esta privación del sentido de la vista tiene una explicación contextual: a los cuerpos que iban a ser arrojados se les extraían previamente los ojos con un corvo, según declaración de los propios militares que cometieron estas acciones de violencia. Por eso la forma verbal "ver" no se utiliza en el poema, salvo hacia el final. Pero además los hechos referidos, como el lanzamiento de los cuerpos al mar, suponen un testigo "de oídas", que ha escuchado hablar de ello, pero que no lo ha presenciado visualmente.

Se habla con recurrencia de lo inconcluso, lo trunco, como de un proceso que no alcanzó a consumarse, o como algo que no alcanzó a decirse, por una interrupción traumática. Se podría decir que el poema mismo es un intento por revertir dicha interrupción, con el objeto de reanudar lo dicho, de recuperar su continuidad fracturada. Lo que no alcanzó a decirse ni nombrarse no es otra cosa que el amor que unía a una colectividad en torno a un mar que prometía un futuro esplendor. Ese amor es referido a través de la imagen de la "carnada rosa", donde flor y carne están unidas metafóricamente en referencia al código erótico (carne en flor, capullo carnal, flor como labio, etc).

Creemos que la representación que se hace del mar en INRI es una subversión del verso "Y ese mar que tranquilo te baña/ te promete futuro esplendor". En efecto, ese mar lleno de carnadas que los peces devoran, convirtiéndose en tumbas donde yacen pedazos y jirones del cielo, constituye el anti-modelo de un mar sereno que se proyecte en todo su presunto esplendor. El esplendor o resplandor mismo es una luz muy clara que despide el sol u otro cuerpo luminoso, y por tanto, sólo puede percibirse por la vista. Así, en un poema donde predomina la privación de la vista, el esplendor o resplandor del mar resultaría invisible, a menos que se lo perciba o describa sinestésicamente. La sinestesia supone una carencia y su compensación y en ese sentido es un tropo que funciona dentro del código del deseo.

Como ya hemos dicho, la sinestesia y la reiteración anafórica son los recursos literarios que más presencia tienen en INRI. La sinestesia cumple aquí la función de suplir la privación del sentido de la vista en el poema; mientras que la anáfora cumple el rol de reiterar lo que no se quiere que se olvide, a la manera de un mantra, de un coro que repite una y otra vez un mismo discurso, para inscribirlo en la memoria de los que lo escuchan, 
pero que no lo pueden ver. En este sentido, INRI es un texto obsesivo, que reitera lo dicho como una estrategia compulsiva de una memoria que se supone frágil y vulnerable, a causa de la privación del sentido de la vista y su potencialidad testificadora.

El mar carnívoro de Chile es el reverso del "mar que tranquilo te baña", en tanto constituye una amenaza de agresión. Es el mar que mutila los cuerpos de los que caen: "Infinitos cielos caen, infinitos cielos de piernas rotas, de brazos contra el cuello, de cabezas torcidas contra las espaldas. Lloran para abajo cielos cayendo en poses rotas, en nubes de espaldas y cielos rotos" (23). En medio de esa escena carnívora y terrible, aparece un personaje femenino, Viviana, de quien se dice que es Chile: "Viviana llora. Viviana oyó torbellinos de peces elevarse por el aire disputándose los bocados de una despedida trunca, de un rezo no oído, de un amor no dicho. Viviana está en la playa. Viviana es hoy Chile” (19). Podríamos identificar a Viviana con la patria o la matria, una presencia femenina que asoma en todo el poema, y que cumple la función de testificar el horror de sus hijos arrojados sobre el mar, como también la de acurrucarlos, protegerlos, llorarlos: "Viviana quiere acurrucar peces, quiere oír ese día claro, ese amor trunco, ese cielo fijo. Viviana es ahora Chile. Acurruca peces bajo el hossana del cielo" (23). Frente al "dulce patria recibe los votos" se erige esta presencia femenina que por su condición estereotipada de género, le es permitido llorar. Viviana, la matria, llora por sus hijos. Viviana es Chile. Por lo tanto, Chile llora. Mientras en la canción nacional, por su condición de canto heroico, se exalta la pulsión bélica, en INRI el llanto se configura como un lenguaje privilegiado, el lenguaje en el que se codifica el dolor de una patria. Chile, entonces, es la madre que llora por sus hijos.

La sección "Flores", por su parte, subvierte el fragmento "Y tu campo de flores bordado/ es la copia feliz del edén” del himno patrio, en la medida en que las flores cubren el espacio vacío que dejan el mar y la cordillera, convirtiendo a Chile en un camposanto, en un cementerio lleno de flores muertas, margaritas y magnolias meciéndose -como en una danza fúnebre- sobre el territorio desalojado de Chile. Carnadas y flores, los dos elementos protagonistas de ambas secciones del poemario, remiten, de distintas formas, al código de la muerte. Las carnadas son cebos para pescar o cazar, compuestos de carne muerta, mientras las flores están en relación metonímica con la muerte, remitiendo a la idea de cementerio o camposan- 
to. "Ese mar que tranquilo te baña" deviene en un mar que tranquilo nos muerde. Mientras el campo de flores bordado se constituye en el testimonio de una muerte colectiva.

El segundo fragmento de la canción nacional que nos ocupa: "Y tu campo de flores bordado/ es la copia feliz del edén”, nos habla de un Chile urdido como un tejido, un artificio, un bordado, que es hecho a imitación del edén, pero no es el edén. Un bordado que supone una herida infligida con una aguja, una manufactura hecha de heridas, suturas que quedan a la vista del observador. Se trata, pues, de flores artificiales que no se corresponden con su correlato natural. Esto sugiere un territorio artificial, un país concebido como una manufactura - un poema- a la manera de una bandera bordada de nieve, cielo y sangre. Es una manufactura del dolor, elaborada en memoria de los muertos y como testimonio de sus vidas (Ansón, 2008; Maderuelo, 2005). Las flores cercenadas del poema de Zurita son una derivación tortuosa de las flores bordadas de la canción nacional: flores arrancadas de cuajo, con la violencia con que se interrumpe un amor nunca dicho. La manufactura desde la que son creadas las flores en INRI no es otra que la manufactura de la muerte, la producción de muertos desde la desaparición y la negación del paisaje.

La sección "Flores" de INRI, tuerce el fragmento del himno patrio como estereotipo del imaginario nacional, resignificando el simbolismo de las flores no ya como imagen idílica del agro chileno, como copia del paraíso terrenal, sino ahora como huella de la muerte y el crimen; transformando la copia feliz del edén en un memorial fúnebre. Recordemos que en el edén no había muerte aún, ni muertos, dado que el hecho que introduce la muerte en la tierra, es el pecado original. El edén es, entonces, el lugar signado por la ausencia de la muerte. La copia feliz del edén sería una imitación de un lugar sin muerte, situación que el poema revierte o invierte, para develar la ironía del fragmento referido. Según el texto bíblico el hombre fue expulsado del edén por haber comido el fruto del árbol del bien y el mal. Así también, INRI nos habla de una expulsión y un castigo. El hombre expulsado del cielo (entendido como el estado edénico por antonomasia) y arrojado a las profundidades de un mar carnívoro, como un cebo o una carnada.

El país es representado como un cementerio, un camposanto, pero también como un extenso jardín, lugar dispuesto para la recreación estética. En el poema el edén desaparece como espacio idílico, incontaminado por 
la muerte y aparece en su lugar un extenso jardín que desplaza el paisaje de Chile, como un inmenso camposanto, donde las flores brotan desde las cuencas vacías de los muertos. La ceguera de aquellos que no podían ver el mar sino oírlo, se convierte en el crecimiento de las flores que dirán lo que no alcanzó a decirse, el amor trunco entre los vivos y los muertos. Las flores en su dimensión amorosa y tanática funcionan como la compensación de una ausencia y un silencio; serán ellas las que dirán lo que no alcanzó a decirse; serán ellas las que dirán que nos aman. El amor trunco, lo que no alcanzó a decirse, los labios que no alcanzaron a juntarse, hallan en las flores su reparación amorosa. "El horizonte son flores, la cordillera de los Andes ahora son magnolias blancas y gimen. Te amo, gimen. Por primera vez desde el comienzo del mundo, lo que las cordilleras jamás nos dijeron nos lo dicen ahora las flores. Las flores que están donde antes estaba Los Andes nos dicen que nos aman" (92). El paisaje confiesa así su amor a los hijos de la patria, en el lenguaje de la ausencia, desde los lugares desaparecidos.

Mientras en este poema se afirma que "Chile entero de flores" (2003: 6) (Chile entero son flores), en Anteparaíso se constataba que "Chile entero es un desierto" (1982: 95). Entonces ¿qué ha ocurrido en Chile entre la escritura de Anteparaíso e INRI, que justifique el sentido de la antítesis? Más que el retorno a la democracia, lo que ha acontecido es un desplazamiento de la manera de concebir un país, la voluntad de borrar un hecho de la experiencia, un fragmento de la vida colectiva de Chile, la intención de corregir la obra como si fuera la propia experiencia, a la manera de un palimpsesto. De este modo, se reasigna una constatación históricamente situada, a un nuevo contexto biográfico e histórico con el que establece una mayor congruencia.

La sección "Flores" habla así de la desaparición del paisaje asimilable a Chile, como país y proyección de un imaginario territorial: Océano Pacífico, Cordillera de los Andes, Valle central y del surgimiento de un nuevo paisaje, compuesto por magnolias blancas que ocupan el lugar de las cordilleras y hortensias azules que ocupan el lugar del mar. Esta desaparición de un paisaje tiene como correlato la desaparición de los cuerpos, arrojados sobre el mar y la cordillera. Un país que desaparece como reflejo de la desaparición de los hombres que lo habitan, a la manera de un paisaje que reacciona ante el dolor de esas personas. Esta reacción del entorno ante un sentimiento humano recuerda la Égloga segunda de Garcilaso de la Vega, 
donde el paisaje reacciona activamente ante el dolor de los pastores, coherentemente con el pensamiento neoplatónico renacentista, que planteaba que cualquier hecho particular tiene su reflejo en el entorno.

La desaparición de la Cordillera de los Andes y del Océano Pacífico puede leerse como la muerte de un país entendido como territorio. La muerte de los componentes de un país o su desaparición, que implica la muerte de su paisaje. No obstante, lo que muere en realidad es el territorio (cordilleras, Océano Pacífico), mientras lo que surge es el paisaje entendido como el vínculo afectivo entre lugar y sujeto. Las flores dicen a los sujetos que los aman, lo que nunca dijeron las cordilleras ni el océano y ahí se establece un vínculo afectivo (también estético) entre el sujeto y el lugar, que convierte al territorio en un espacio de contemplación: en paisaje. El amor se muestra como el sentimiento que congrega una colectividad dispersa, fracturada, y su función reparadora es capaz de revertir la muerte, como situación de silencio e incomunicación. Las flores del Pacífico y la Cordillera dicen a los hombres que los aman: "Y se lo dicen a ustedes, asesinos, destrozadores de hombres, los maravillosos aromos del campo y las magnolias que crecen donde antes estuvieron las cordilleras y las azuladas hortensias que crecen donde antes estuvo el pacífico lo dicen" (2003: 95).

Este nuevo paisaje se muestra así, por otra parte, como un Chile difunto rodeado de flores, un memorial fúnebre que testimonia la desaparición de un territorio y sus habitantes. Así, las flores que hablan del amor pueden ser reconocidas como el coro que oficia una ceremonia fúnebre, o un réquiem. Se podría pensar a Chile como las exequias de un país muerto, y su paisaje como signo de una pasión, una muerte y una resurrección, en un contexto en que la historia misma se revela como un discurso trunco, del que el poema es un texto compensatorio. El momento en que se vinculan los dos fragmentos referidos de la canción nacional como imágenes simbólicas corresponde a los versos "cosechas llovieron desde el cielo, frutos maduros sobre los campos labrados del mar" (Zurita, 2003: 22), donde "campos labrados" equivale a "campos bordados" no ya de flores, sino de cuerpos humanos como frutos que caen sobre el mar.

¿Cuál es el sentido de subvertir dos fragmentos tan significativos de la canción nacional? Creemos que dicha intervención obedece a la voluntad de poner de manifiesto su incongruencia con un contexto histórico determinado, y a la vez su desfase con una imagen de país que se ha vuelto in- 
compatible con su representación lírica e idílica. Un país donde los cuerpos de los detenidos políticos son arrojados vivos sobre el mar carnívoro es, sin duda, incongruente con cualquier representación idílica que se haga de él. Asimismo, un país donde las flores nacen de las cuencas vacías de los muertos, resulta incompatible con su representación edénica. Se trata entonces de develar la latencia de una muerte colectiva tras el lugar común de la belleza asignable a nuestro territorio, una muerte que conlleva una desaparición traumática. Por eso, la Cordillera de los Andes y el Océano Pacífico desaparecen dejando enormes fosas desde las que ahora crecen las flores, como testimonio fúnebre de una historia truncada. Se podría decir que el poema devela el funcionamiento irónico de los dos fragmentos del himno patrio a los que nos hemos referido, con la intención de mostrar su incongruencia con un fragmento de la historia de Chile.

Ambos fragmentos no son dichos o denotados en el poema; pertenecen al ámbito de lo connotado en un contexto que permanentemente alude a lo no dicho, a lo que no alcanzó a decirse. El texto de Zurita trabaja persistentemente con la dimensión de lo silenciado, de lo no dicho. Nos parece que los fragmentos de la canción nacional referidos en este trabajo y que no aparecen dichos en el texto de Zurita explícitamente funcionan como matrices de sus imágenes y símbolos, pero además refuerzan lo que INRI dice: la desaparición de los cuerpos de las víctimas de la dictadura militar. Lo no dicho refuerza el sentido de lo desaparecido. El paisaje en INRI no es, en ningún caso, un paisaje cantado, ni descrito como una realidad externa, plena, sino un paisaje construido como una función que tiene por objeto reinterpretar dos fragmentos del himno patrio y su relación con un fragmento de la historia de Chile. Dicha función revela la voluntad de construir el paisaje como un inmenso memorial, donde la pasión y la redención de las víctimas es representada a través de una alegoría en que mar, cordillera y flores, en sus desplazamientos respectivos, encarnan el dolor, el castigo y la posibilidad de una reparación.

La pasión, en sus dos sentidos; amor y padecimiento, moviliza la alegoría construida por INRI, como la voluntad de dar cuenta de un fragmento de la historia de Chile, revirtiendo su lectura institucional. La geografía misma, modificada por acción de esa pasión desbordante, se vuelve una imagen representativa de la muerte y la resurrección de un país. Zurita hace llorar a Chile por sus hijos, y a las flores las hace decir lo que nunca 
habían dicho: que nos aman. Y ni ese mar que tranquilo nos baña ni ese campo de flores bordado lograrán representar fielmente el sentido cabal de nuestra pasión, de nuestro dolor, nuestro amor, nuestro INRI final de los paisajes.

\section{Referencias}

Ansón, A (2008). Territorios y paisajes. Modelos para pensar fotografía y literatura, tal vez soñar. En J. Maderuelo (ed), Paisaje y Territorio (pp. 227254). Madrid: Abada.

La Biblia Latinoamericana (1972). Madrid: Ediciones Paulinas.

Maderuelo, J. (2005). El paisaje: génesis de un concepto. Madrid: Abada editores.

Manrique, J. (1983). Coplas a la muerte de su padre. Madrid: Editorial Castali.

Zurita, R. (1982). Anteparaíso. Santiago de Chile: Editores Asociados. . (2000). Poemas militantes. Santiago de Chile: Dolmen. . (2003). INRI. Ciudad de México: Fondo de Cultura Económica. 